while a positive result was not much more to be trusted. In regard to the administration of quinine not only must the dose be adequate, but it must be so given that it shall be absorbed. A catarrhal condition of the mucous membrane was usual in severe malarial attacks, and such a condition was very unfavourable to absorption, so that in these cases the quinine ought to be given hypodermically or by enema. To give it in the tablet or coated pill form was a most dangerous method in severe cases, and most unsatisfactory for purposes of diagnosis. Another interesting statement was made by Dr. Manson in regard to the length of time that an infection with malaria can persist. This he placed at three years, and if we put this side by side with his other statement as to indigenous malaria being a thing of the past in England, we may draw the important conclusion that a case of fever in a patient who has not been in a malarious country: for three years or more is not a case of malaria.

\section{OVARIAN DYSMENORRHCEA.}

As ill-chosen name leads to much mischief, and in medicine may perpetuate much false pathology. As bearing upon this we would draw attention to some remarks recently made by Dr. Herman ${ }^{1}$ on the subject of " ovarian dysmenorrhœa." In some cases of dysmenorrhœa, he says, the patient refers her monthly pain especially to the situation of the ovary. She points to a spot about two inches internal to the anterior superior iliac spine, and says the pain is there; she may add that it goes through to the back, indicating a spot over the sacro-iliac synchondrosis of the same side, and when the fingers are pressed down upon the spot pointed to, the patient manifests more pain than when pressure is applied anywhere else. Sir James Simpson applied to cases presenting this kind of monthly pain the name of "ovarian dysmenorrhœa." This term, however, is nothing but a name-a label. It conveys no information and helps in no way in treatment. It would seem to imply that the pain is due to some condition of the ovary, and a bypothetical pathology of the ovary has been constructed to account for such cases. Various morbid conditions have been described which have been supposed to cause pain, such as "cirrhosis," "congestion," "œdema," "dropsy of follicles," etc. But in the best known and most conspicuous disease of the ovary-cystic diseasethere is as a rule no pain until the cyst is big enough to press upon something else, and as to the other ill-marked morbid conditions which are supposed to cause such suffering, "all I need tell you," says Dr. Herman, "is that if you were to put upon a plate half a dozen ovaries, not much enlarged or adherent, removed from women who had this ovarian pain, and put with them half a dozen other ovaries taken from the bodies of women who were accustomed to menstruate without pain, there are no criteria by which anyone could pick out the ovaries of those who had pain when they menstruated. So long as we cannot distinguish a painful ovary from one which is not painful, it is idle to say that we know anything of the morbid conditions of the ovary upon which pain depends."

\section{Brit. Med. Jour., May 17.}

\section{SPASMODIC DYSMENORRHEA.}

The matter is otherwise, however, in regard to spasmodic dysmenorrhœa. Menstrual pain of extreme severity is almost always of the spasmodic kind. It is common for patients to say that when it is present they cannot lie still, they roll about with pain, it doubles them up, keeps them awake at night, and makes them perspire and sometimes faint. In about one-fourth of the cases it causes vomiting. Its usual duration is less than 24 hours, and it only exceptionally lasts longer than two days. But patients who suffer from uterine congestion may have two kinds of pain, the aching due to pelvic congestion which may precede the flow by several days and the spasms of uterine colic which only last a few hours, and this is a matter which must be inquired into, as women may not always properly distinguish between the two. The pain of spasmodic dysmenorrhœa comes in sudden, sharp pangs, and between these twinges there is either no pain or a dull general aching in the pelvic region. Each attack of pain is of short duration, usually only a minute or two. The natural cure of spasmodic dysmenorrhœa is by pregnancy. The best drugs for the relief of uterine colic, says Dr. Herınan, are antipyrin and phenacetin. In slight cases they give adequate relief, and as we know not of any harmful results from their occasional use, if these drugs relieve there is no need for further treatment. If these drugs fail, powerful narcotics may be required, but it is a bad thing for a young woman to use these drugs every month, and if this becomes necessary local treatment is preferable. The local treatment of spasmodic dysmenorrhœa is to dilate the cervix by the passage of bougies. In a few cases 10 grains of guaiacum resin in a tablespoonful of malt extract, twice or three times a day, beginning a week before menstruation is expected, will remove the pain and sometimes will cure. How it acts, and in what cases it will succeed are unknown.

\title{
Progress in Genito-URINARY SURGery.
}

\section{(Continued from page 117.)}

The Treatment of Syphilis.-Winfield Ayres ${ }^{12}$ has written on this subject. He points out that treatment with mercury was begun over 400 years ago. The disease is so insidious and takes so long to eradicate that whatever preparation is selected to deal with it must be one which is easily borne and will not cause any general disturbance. Those who believe that the constant, as distinguished from the interrupted treatment is the best, systematically prescribe mercury for three years. Ayres is certain that the full dose of mercury should be constantly given for about that length of time. The rule should be to first find the point of tolerance and then hold the dosage just below that point. The treatment should be begun just so soon as the diagnosis of syphilis can be made, whether the eruption has appeared or not. The initial lesion assumes one of three forms-an ulcerated sclerotic nodule, an eroded sclerotic nodule, 